\title{
SCHOOL BUILDINGS AND DESIGN IN MALAYSIA
}

Murad bin Mohammed Noor

\author{
Director, Planning and Research Division, \\ Ministry of Education, Malaysia
}

The Ministry of Education manages administratively and financially the entire school building programme for the whole country. Until 1962, the Ministry had its own architectural works division, which either designed its own school projects or requested local consultant firms to execute the work.

Since then, however, the design work and construction has been the responsibility of the Public Works Department, which is part of the Ministry of Works, Posts and Telecommunication.

The establishing of programmes for school building work is somewhat recent in this country and was introduced in 1960 when the first five year plan, known as the First Malaya Plan, was introduced. The table below shows the current school building programme.

Table I

Current School Building Programme ( $\$$ M million)

\begin{tabular}{|c|c|c|c|}
\hline & Programme & $\underset{\$}{1966-70}$ & $\begin{array}{c}1971-75 \\
\$\end{array}$ \\
\hline $\begin{array}{l}\text { (I) } \\
\text { (II) }\end{array}$ & $\begin{array}{l}\text { West Malaysia only } \\
\text { (a) Primary } \\
\text { (b) Secondary } \\
\text { (c) Technical education } \\
\text { (d) University } \\
\text { (e) Teacher training } \\
\text { (f) Other programmes } \\
\text { East Malaysia }\end{array}$ & $\begin{array}{r}48.5 \\
100.7 \\
10.8 \\
24.4 \\
9.7 \\
19.0 \\
42.5\end{array}$ & $\begin{array}{r}55.09 \\
154.43 \\
42.86 \\
87.05 \\
3.00 \\
27.68 \\
78.37\end{array}$ \\
\hline & Total Expenditure & 255.6 & 448.48 \\
\hline
\end{tabular}

Planning Procedures

The education budget for the year is included in the National Budget that is passed by Parliament around November/December of the previous year. Capital items are voted and approved in very much the same way as the recurrent expenditure, except that in the case of capital it ems these have to be approved first by the Finance Committee of the National Development Planning Committee (NDPC), which operates within the framework of 
the Prime Minister's Department. However, it must be noted that the total development annual expenditure for the next five years cannot exceed the ceiling approved under the Second Malaysia Plan without the approval of the NDPC. Funds are directly controlled by the Ministry of Education, which in turn allocates funds either to the Public Works Department (PWD) for the construction of buildings or to the Chief Education Officers of the States for expenditure on furniture and equipment.

Special proformae are prescribed by the Treasury for the submission of development projects for approval. Each project must be fully prepared and set out in accordance with the basic format laid out below. This is done after consultation with Chief Education Officers of the various States or other relevant authorities, who in turn would have consulted the respective local authorities and school boards. The proposal must establi sh that the project has been soundly conceived, taking into consideration the technical, engineering, economic, financial and organisational aspects.

The type of information which must accompany each proposal is indicated hereunder:

(a) Background information on the projects (e.g. the contribution the project will make towards the fulfilment of the general objective of the Ministry).

(b) The project:

(i) Description of the project and its location, etc.

(ii) The stage of preparation of the project.

(ii i) The limiting factors and special problems e.g. suitability of soil, transportation, etc.

(iv) The proposed implementation schedule of the

(v) project.

(v) The organisational and administrative arrangements of the project.

(c) Cost estimates:

(i) Capital costs.

(ii) Recurrent costs.

(d) Manpower requirements.

(e) Benefits and justification - this section is really the heart of the brief. Here should be presented an objecti ve and comprehensive statement regarding the importance of the project.

(f) Foreign assistance requirements.

Design and construction

The size of the school site generally depends upon the type of school and the educational programme. Table II below gives the minimum areas required for the various types of school. 


\section{Table II}

Minimum Area Required for Schools

Level

Primary

Lower secondary

Upper secondary

Upper secondary vocational

Upper secondary technical

\section{Average}

6 acres

6 acres

8 acres

20 acres

20 acres

The building design and pattern of school buildings are based upon educational, sociological, and sanitary requirements, taking into account such factors as climate, surroundings, economic situation and building techniques. Therefore the design of school buildings in this country is the result of close collaboration between educators, architects, cost engineers, surveyors, civil and structural engineers, and health officers. In designing new buildings, possible changes in teaching methods are also taken into con sideration.

Generally speaking, standard plans are used in all school building construction, but the component units of the buildings are quite flexible and adaptable to meet the varying local conditions and also the evolution of educational ideas.

The standards used in school planning are summarised below in reference to particular examples (all sizes are given as net area):

(a) Room sizes (Secondary schools)

\begin{tabular}{l} 
Maximum \\
no. of \\
students \\
per unit \\
\hline
\end{tabular}

Total area in

Accommodation unit per unit sq.ft. (net)

Area per student

St andard classroom

40
40
24
24
24
24
24

710 in sq. ft.

Science room

950 (net)

Domestic science room

Needlework room

Metalwork shop

Electrical workshop

Woodwork shop

1190

950

1700

1000

1190

(b) Window areas in relation to room sizes

Standard natural light for educational rooms (wi ndow area including screened ventilation area) is about $37 \%$ of the room's net floor area.

(c) Floor to ceiling heights

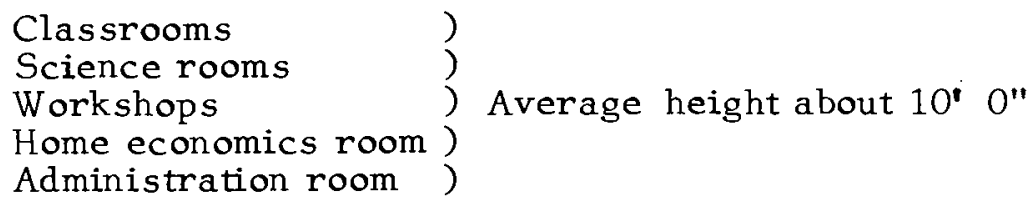


For specialised rooms such as assembly halls, gymnasia, etc., no standard plans exist.

(d) Sanitary standards

Unit

Girls' toilet

Water closets

Wash basins

Boys' toilet

Water closets

Urinals

Wash basins

Changing rooms

Showers

Staff (female)

Water closets

Wash basins

St aff (male)

Water closets

Urinals

Wash basins
No. of people per unit

Minimum $\quad$ Maximum

$\begin{array}{rr}35 & 55 \\ 24 & 38 \\ & \\ 45 & 120 \\ 29 & 45 \\ 22 & 35\end{array}$

53

84

$\begin{array}{ll}7 & 10 \\ 7 & 10\end{array}$

$\begin{array}{rr}15 & 20 \\ 4 & 4 \\ 7 & 10\end{array}$

Water supply

Average daily consumption per head per day:

(a) Boarding school - maximum 40 gallons for the boarders.

(b) Day school - about 10 gallons per school session.

Water in urban areas is provided by the government (either the Public Works Department or the municipalities). In rural areas, where there is no public water supply, it comes from the schools' own wells. There is no problem in getting an adequate water supply throughout West Malaysia.

Drainage and sewage disposal

Sewage and drainage of wastes and storm water is done in urban areas through the public sewage, where this exists. In areas without public sewage, it is done through the school's own septic tank.

Artificial lighting

Electrical light is normally used during the rainy seasons and for evening classes.

The volage is $230-240 \mathrm{v}, 50$ cycles $A C$.

In some remote parts of the country, schools depend on their 
own generators for their supply of power. The table below indicates the standards used for light levels for different units :

(a) Classrooms
Assembly room )
Laboratories

Home economics) (b) Workshop )
Art room

(c) Administration rooms, (e.g. general office) 3 General Headmaster's office \& staff room, library) 10 lighting Watt per sq. ft:

\section{Sun-screening and protection}

In order to provide minimum interference from the sun, and hence maximum thermal comfort conditions both for the pupils and the teachers, all the classroom blocks are ori ented East-West. Where this is not possible, due either to site diff iculties or shape of the lot, every effort is made to keep any variation to within $10^{\circ}$ of this line.

For further protection from the sun, screening and protection of window walls are effected by louvres, and/or overhanging floor slabs at first floor level.

\section{Ventilation}

All teaching rooms have natural cross ventilation. The ventilated area - wire mesh screen - is about fifteen per cent of the room's floor area. This percentage does not include the ventilated area obtained from louvred windows.

Arti ficial ventilation is only used in very rare cases, e.g. the library and/or administration area may have ceiling fans provided.

Once these standard plans have been designed and approved, copies are sent to all the State and District Engineers, who must utilise them for all school buildings irrespective of their locality. Any deviation or alteration to the standard plans must meet with the approval of the Assistant Director, Public Works Department, in charge of the Education Works section of the P.W.D.

Once the layout of a school has been designed and approved by the Head Office of the P.W.D. and the respective Chief Education Officer, and after the Bills of Quantities/specification have been prepared by the Quantity Surveying Branch, the P.W.D. then invites tenders from appropriate grades of contractors registered with it.

However, any intended change in the school curriculum is conveyed to the P.W.D. which in turn modifies the building plans to meet the new needs. These plans are then sent to the relevant sections of the Ministry for approval. As soon as approval is obtained, the standard plans are then modified. A few examples where standard plans have and are being 
modified to meet such innovations in teaching methods and curricula are:

(a) Workshops

The content of Industrial Arts in secondary schools has been enlarged recently. Power mechanics and electricity have now been introduced in addition to metal and wood-work. This has given rise to the need to modify the old workshops and the existing standard plans to accommodate the additional activities.

(b) Science laboratories

The teaching of science in Malaysia is at present undergoing changes with emphasis on practical work in which the pupils themselves endeavour through experiments to find out for themselves the principles relating to the topics unde $r$ study, rather than verification of principles explained in lessons. This is what is commonly known as integrated science. Action is now being taken by the Ministry's science centre to design new laboratories which will provide space for group work, facilities for display of audio-visual aids, etc. Various types of movable furniture for these laboratories are also under consideration.

Conclusion

In Malaysia, the school building programme has kept pace with demand for education. However, recent trends in education indicate that there is a need for more specialist types of teaching space, particularly at the upper secondary level. The Ministry and the P.W.D. are now actively engaged in studies on the need to build more schools, more economically, and with more intensive utilisation of specialist teaching space so as to offset additional costs.

It may also be relevant to note that a seminar on Costs and Utilisation of Secondary Schools in Malaysia was held in March 1971 in collaboration with Unesco experts from the Asian Regional In stitute for School Building Research.

Among other decisions taken at the seminar, it was agreed that, if Malaysia is to take advantage of the changes and innovations resulting from the development of technology, it would be necessary to look into the possibility of establishing an Educational Facilities Development Group. This group, which is essentially an inter-disciplinary team, will consist of educationalists, architects, engineers and cost officers. The function of this group will be to study school programming, space utilisation and costs to the ultimate advantage of the school building programme. Malaysia is at present seeking the assistance of the Asian Institute for School Building Research in establishing this unit. 